\title{
Homelessness and Residential Care
}

\author{
J. Godwin Premsingh ${ }^{1}$, Wesley D Ebenezer ${ }^{2}$ \\ ${ }^{I}$ (Associate professor, Bishop Heber College, India) \\ ${ }_{2}^{2}$ (PhD Research Scholar, Bishop Heber College, India)
}

\begin{abstract}
Homelessness seems to have been rising throughout the world. Over 100 million people live without shelter (almost one third of the world's population) and the harder truth is that over 11 million children live on the streets.

There have been shelter homes and facilities for the homeless children in India started by both government and non-governmental organization. This study investigates the facilities and care rendered by the institutions in Tiruchirappalli city in Tamil Nadu, India. The study also points out lacunas in the institution for the homeless.

The study pleads for better facility of the homeless because every child has the right to lead a life, free from discrimination, inequality and exploitation. This is the key to our residential care and foremost to nation building.
\end{abstract}

Keywords - Homelessness, Residential Care, Vulnerable Children, Homeless Children, Child Care

\section{INTRODUCTION}

"Everyone has the right to a standard of living adequate for the health and well-being of himself and of his family, including food, clothing, housing and medical care and necessary social services, and the right to security in the event of unemployment, sickness, disability, widowhood, old age or other lack of livelihood in circumstances beyond his control."

- Universal Declaration of Human Rights, article 25, par. 1

Homelessness categorizes the condition of people without a regular dwelling because they are unable to acquire, maintain regular, safe, and adequate housing, or lack "fixed, regular, and adequate night-time residence."

A homeless person is defined into three categories. In general it is said about an individual, who lacks a fixed, regular, and adequate night-time residence; and an individual who has a primary night-time residence that is

1. a publicly supervised or privately operated shelter designed to provide temporary living accommodations (including welfare hotels, congregate shelters, and transitional housing for the mentally ill);

2. an institution that provides a temporary residence for individuals intended to be institutionalized; or

3. a public or private place not designed for, or ordinarily used as a regular sleeping accommodation for human beings.

\section{HOMELESSNESS - THE FACT}

Housing is a basic human need. In spite of that, the statistics of United Nations Commission on Human Rights in 2005 notes that an estimated 100 million people, which is one-quarter of the world's population, live without shelter or in unhealthy and unacceptable conditions.

Over 100 million people around the world have no shelter whatsoever. The health consequences of this level of homelessness are profound. The Action Aid in 2003 had found out in a study that there were 78 million homeless people in India alone. CRY (Child Relief and You) in 2006 estimated that there are 11 million homeless children living on the street. The statistics are grim. What is worse is that very little is known of what it means to be part of such horrific numbers.

\section{HOMELESS CHILDREN - THE FACT}

A person under the age of 18 who is living in a shelter, motel, vehicle, campground, on the street, in sub-standard housing, or doubled-up with friends and relatives due to a lack of housing. Runaway, throw-away teens and abandoned children are all considered homeless.

According to a report published by the United Nations, there are $\mathbf{1 5 0}$ million children aged three to 18 years on our streets today and their numbers are growing fast. $40 \%$ of the world's street children are homeless, the other $60 \%$ work on the street to support their families. The UNICEF, World Health Organisation (WHO) and several NGO's have got disputing figures in their account of street children. According to CRY (Child Relief and You) about 60 million Indian children under the age of 6 live below the 
poverty line. The problem has become particularly acute for homeless children, one-fifth of these children receive no education.

According to Indian Embassy figures, there are 314,700 children living on the streets of Bombay [Mumbai], Calcutta [Kolkata], Madras [Chennai], Kanpur, Bangalore and Hyderabad, and another 100,000 live in New Delhi; however, these numbers may not reflect the true picture, as accurate census information is difficult to collect. In truth, millions of India's children are denied even the most basic rights of survival and protection. Children living on the streets are especially vulnerable to victimization, exploitation, and the abuse of their civil and economic rights

\section{REASON FOR HOMELESS CHILDREN}

Children are abandoned, orphaned, or thrown out of their homes. They have no choice and finally end up on streets. It may be because of the mistreatment, neglect or that their homes do not or cannot provide them with even the basic necessities. Many children also work in the streets because their earnings are needed by their families. The reasons for these children's homelessness may be interlinked with social, economic, political, environmental causes or a combination of any of these. UNICEF defines street children as "children who work on the streets of urban areas, without reference to the time there or to the reasons for being there"

WHO offered the following list of causes for this phenomenon called homelessness, which is seen below in Fig 1.

Fig 1

Causes of Homelessness

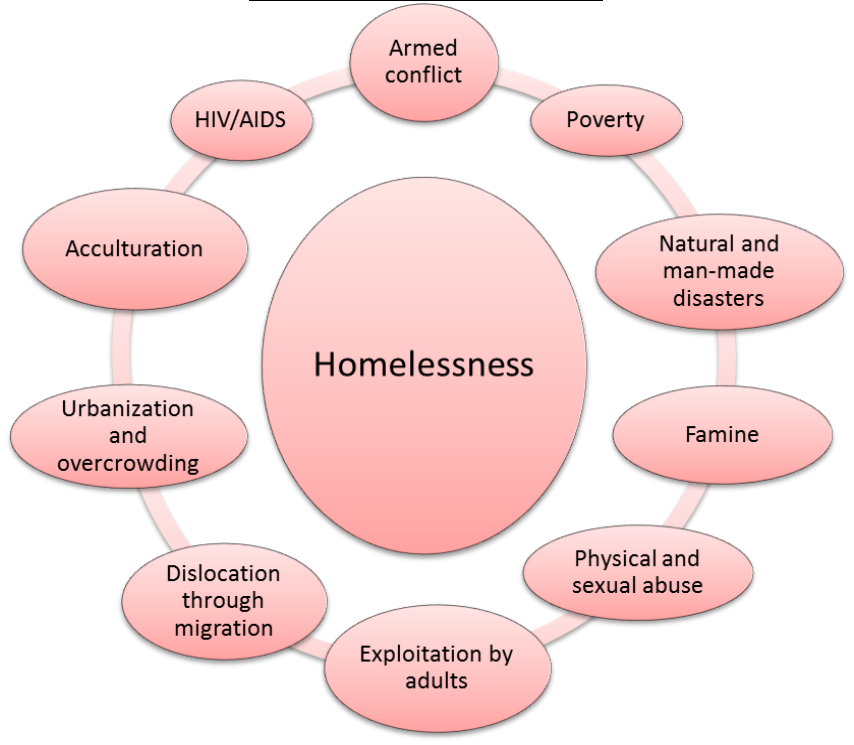

\section{RESIDENTIAL CARE}

Residential care can be defined as 'a group living arrangement for children in which care is remunerated by adults who would not be regarded as traditional carers within the wider society' (Glenn Miles \& Paul Stephenson, 2001). The Residential care center gives a Child a Family which provides children with holistic restorative care. The shelter becomes their home for the period that investigations are done to find their parents, extended biological family, or to match them with suitable foster parents or to take care of them till they reach adulthood and mature enough to merge into the mainstream society.

Therefore residential care is run by groups of caring adults who are committed to children and provide a family environment where there is unconditional acceptance and support on an individual basis. It could be argued that this kind of care is in the best interests of children where there are no alternatives: for example, those who are either in abusive or destructive family environments or cannot settle with a small foster family (Glenn Miles \& Paul Stephenson, 2001).

\section{RESEARCH METHODOLOGY}

The following data are the information collected from the institutions for homeless children at Tiruchirappalli. It was conducted among the 40 NGO's who are providing services to homeless children. 


\section{A. Research Design}

This study is a descriptive study based on interview schedule as the source of evidence. It is an attempt to describe the various facilities \& care institutions cater to homeless children. The researcher tries to understand the quality programme for the homeless children by analysing the data and interpreting various facilities these institutions offer the children of the homeless. The study looks at the service offered by the institutions for the homeless children. It also looks at the various awareness and educational program; and personal Institutions for the services rendered to these homeless children.

\section{B. Area of the Study}

The study was undertaken in Tiruchirappalli city. It covered the 40 Institutions for the homeless children in the city. The Census method was adopted for the present study.

\section{Sampling Frame}

The purpose of the present investigation is to analyse the facility and care rendered to the homeless children in the institutions. The study looks at the service offered, psychosocial care given to the homeless children in the Institution. It also looks at educational, awareness programs and other activities conducted by the Institution for the welfare and development of homeless children. Therefore, the sample comprises of 40 respondents from the entire universe of Institutions for homeless children in Tiruchirappalli, Tamil Nadu. The CEOs of each 40 Institution for the homeless were the respondents.

\section{Method of Data Collection}

The whole universe is covered; therefore Census method is used in this study. There are 40 Institutions for the homeless children in the target area of Tiruchirappalli, Tamil Nadu. The CEOs of these Institutions were taken for the study using an interview schedule.

\section{Residential CaRe fOR HOMEless ChILdREN}

The Residential care center gives a 'child' a 'family', which provides children with holistic restorative care. The shelter becomes their home for the period that investigations are done to find their parents, extended biological family, or to match them with suitable foster parents or to take care of them till they reach adulthood and mature enough to merge into the mainstream society.

Therefore, the residential care means being cared for by generally unrelated people, and we believe that the essence of family life is the nurture and unconditional acceptance of children by adults in an individual adult-child relationship. The residential care may fail to provide this individual. In fact the larger and more institutional the residential care, the less likely such individual nurture and unconditional acceptance is. The 'key-worker system', ensuring that each child has someone who is responsible for them, goes some way in seeking to prevent a 'faceless' care system. By placing a selected case worker with each child, many basic cares needs can be reviewed and carried out regularly. But, is this enough?

In Tiruchirappalli a city in the state of Tamil Nadu has about 40 homeless residential care centres for the homeless children. Their is a parallel world of struggling to survive for these homeless children, a world where adolescent angst is about whether another meal comes your way, or whether you can sleep through the night, unmolested, on a hard patch of pavement. These children go through a lot of trauma when they come. Boys scooting between train tracks, darting in and out of newly empty railway carriages, are a common sight. Many are harassed or beaten by police officers, or sexually abused by predatory adults. A fair number resort to sniffing glue. Some beg, others steal etc... are common sites in Indian cities 
Fig: 2

\section{Pattern of addiction in street children perceived by Institution}

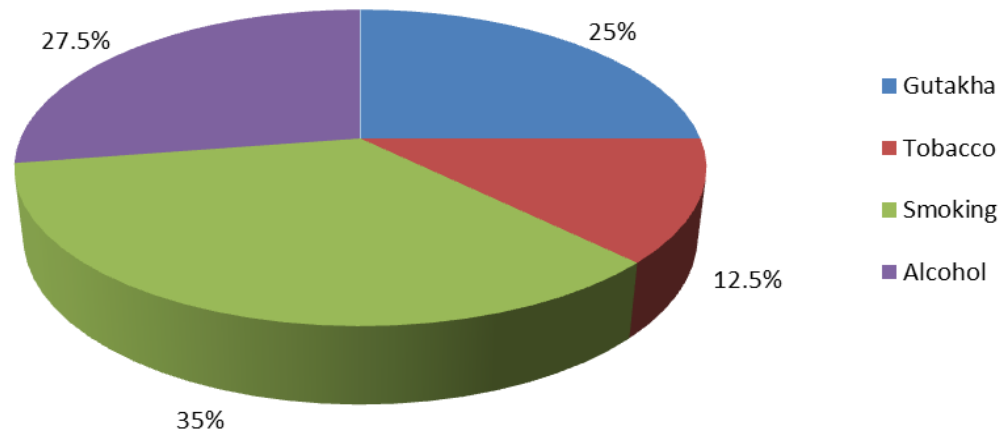

Studies such as the National Survey on Drug Use and Health, formally called the National Household Survey on Drug Abuse, reported by the Substance Abuse and Mental Health Services Administration, indicate that some children are already abusing drugs at age 12 or 13, which likely means that some begin even earlier especially for children from the street. Fig: 2 shows the pattern of addiction among street children in rescued to the institutions. The figure shows that smoking and alcoholism are prominent among these kids.

Fig: 3

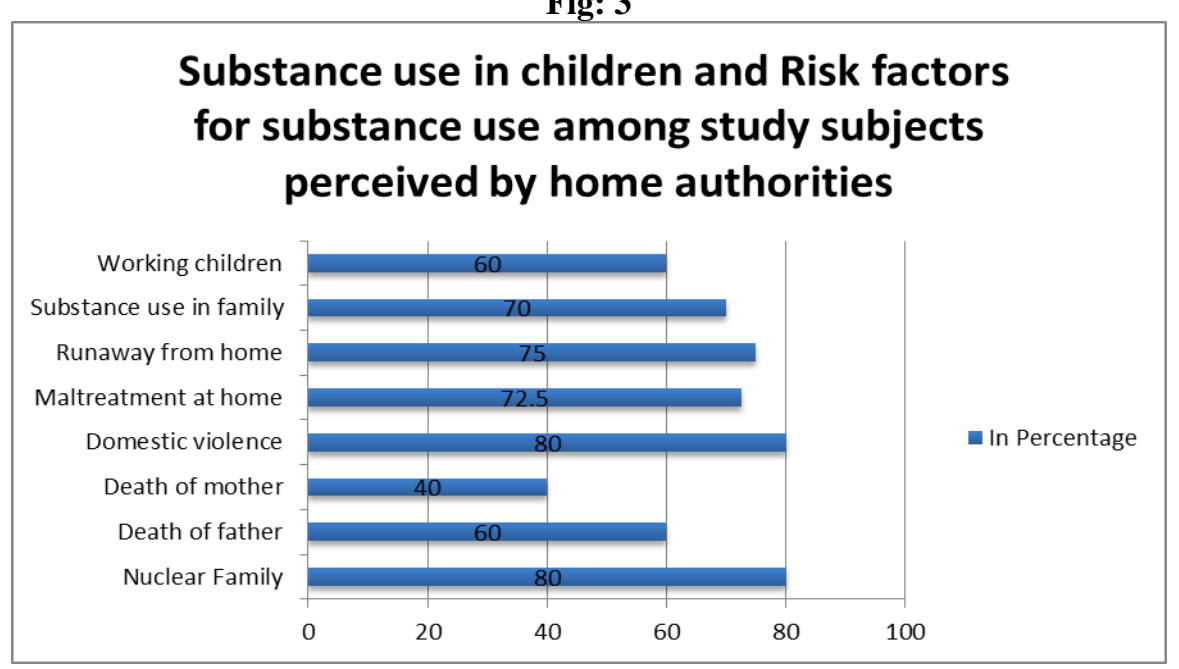

Fig: 3 show the risk factors relating to substance abuse for the homeless children. It shows that due to domestic violence in family and a child coming from nuclear family, the percentage of substance abuse was at his highest at $80 \%$ chances. Children's earliest interactions occur in the family; sometimes family situations heighten a child's risk for later drug abuse, for example, when there is:

$>$ a lack of attachment and nurturing by parents or caregivers;

$>$ ineffective parenting; and

$>$ a caregiver who abuses drugs.

Other factors - such as drug availability to working children, runway children abuse at home and death of either father or mother are risks that can influence young people to start abusing drugs. 
Fig: 4

sexually active street child reporting selected sexual behaviours perception by Institutions

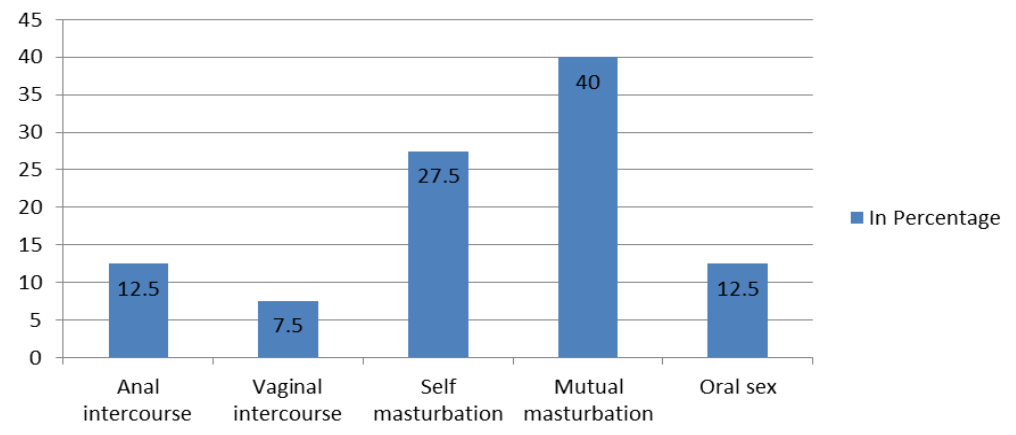

As Fig: 4 shows Mutual masturbation is at its highest with $40 \%$ and self-masturbation at $27.5 \%$. The vaginal and Anal intercourse at $7.5 \%$ and $12.5 \%$ respectively.

Street children have a great need to fill the void of normal relations because many have left their families or do not have a family. Street boys sometimes describe sex as "play between friends". Comfort sex is often exploitative in nature, even though such a relationship provides the child with shelter, basic needs and protection.

Sometimes, street children use sex as a way of expressing physical power. The younger street children comply for fear of being beaten. Some street boys have said that they have sex with prostitutes because it is a symbol of strength and being a 'real man', and to show friends that they are in control.

A risky sexual behavior is one that increases the likelihood of adverse sexual and reproductive health consequences. These health consequences may include unwanted pregnancy, unsafe abortion, HIV/AIDS and STDs.

Therefore, the residential care Institutions have personnel's from various fields, appointed by these Institutions to take care of these children at risk.

Fig: 5

Morbidity pattern among the children perceived by head of the institutions

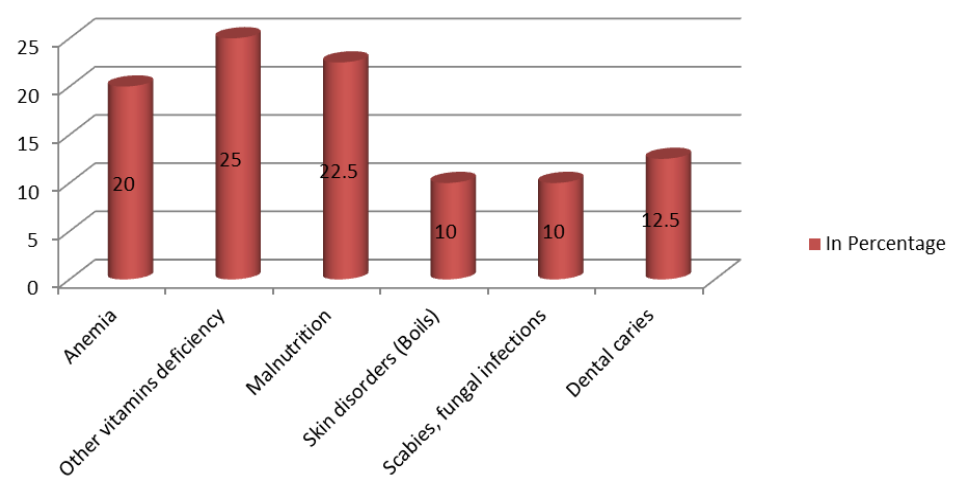

Fig: 5 denotes morbidity pattern of these children. Anemia, malnutrition, Vitamin deficiency and dental caries were commonly observed in the children. Our finding is supported by Patel (2006), who reported malnutrition and anemia in majority of the street children in their study. These morbidities are as a result of poor diet, poor hygienic condition and ignorance of these children regarding nutritive food. $26 \%$ of these children had fungal infection of skin and nails while $14 \%$ had injuries in hand and feet as occupational hazards. Our finding is in accordance with the findings of Gupta (2007) who have also reported these occupational hazards in their study. Prolonged working hours especially in unhygienic conditions makes these children vulnerable to occupational hazards. 
Fig: 6

\section{Personnel from Various Fields}

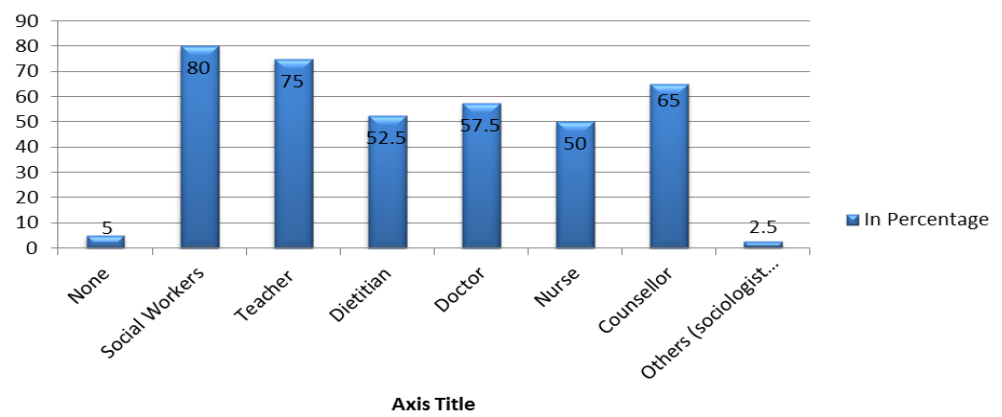

This fig: 6 shows that $5 \%$ of the residential care Institution did not have any special personnel i.e. social workers, teachers, dietician, counsellor etc... expect for the care takers. Only $2.5 \%$ sociologist /psychotherapist /speech therapist were found in these Institutions and 35\% of the Institute do not have a counselor. Homeless children are children at risk and they are psychologically ill because of the trauma they have to put-up with before they reach the residential care institution. In the Institute also these personnel's are substitutes for their parents and therefore it is necessary Psychotherapist. As for Doctors and the residential care Institution have referrals to nearby hospitals when needed.

Fig: 7

\section{Sevices provided by the Institution}

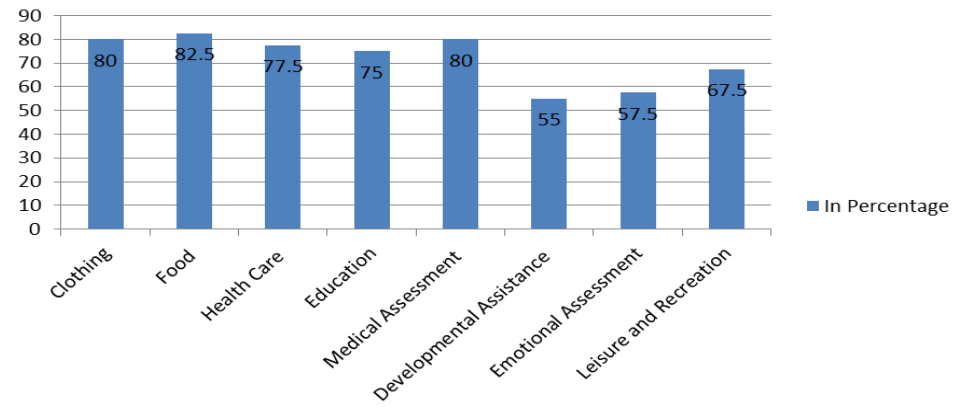

Fig: 7 shows the services provided by the institutions. More than $70 \%$ of institutions provide the basic amenities, Education, health care and medical assessment. It is clear that not all the institutions provide all the facilities stated above. The major reason is unsound fiscal condition. They do not have enough sources to fulfill the needs of the homeless children. The researcher concluded that Institutions have long been in existence, and are a main provider of welfare and other services, especially for the poor. Institutions have been at the forefront of homeless children work in several countries in the region for some time. It is noted, however, that relatively few Institutions have a particular focus on children Development assistance, which is only 55\% and emotion assistance being just $57.5 \%$ which is very essential for the rehabilitation of a homeless child.

Fig: 8

\section{Suggestions Given by the Institutions}

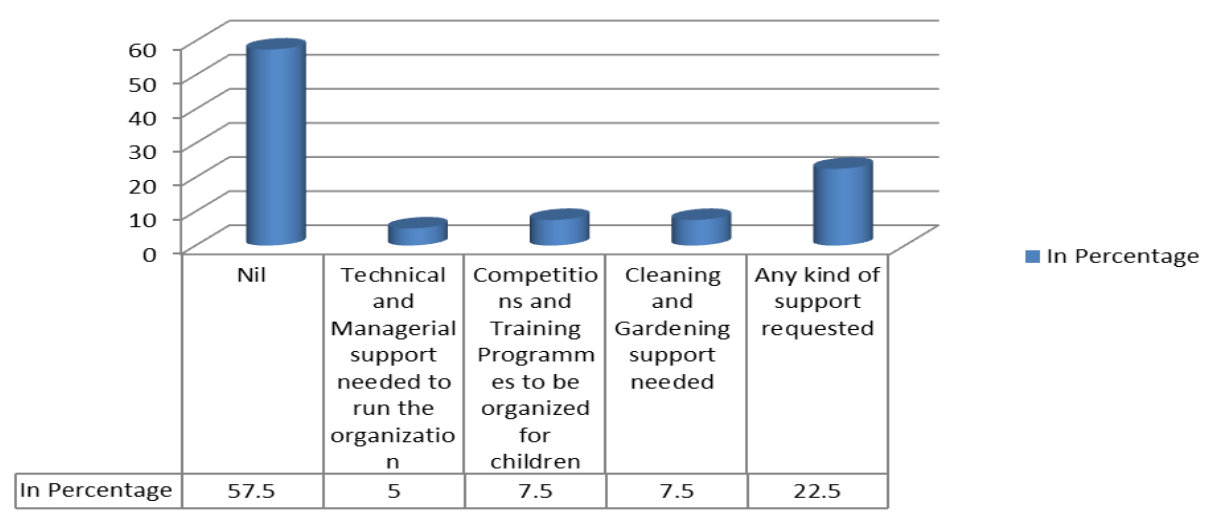


The fig: 8 shows that $57.5 \%$ do not need any services of the institutions for Homeless children in Tiruchirappalli. But the remaining institutions have proposed that they need assistance and help. This shows the lack of services in particular institution. They can perform still better if they will be provided the proposed services.

\section{CONCLUSION AND SUGGESTION}

The Asia-Pacific Region is home to nearly half the world's children, including large numbers of homeless children. This paper provides an introductory snapshot of issues concerning "homeless children" in this vast and culturally diverse region. Although the term homeless children is neither a precise, nor very useful classification for children "on" or "of" the street, the term does serve as a point of engagement in considering the variety of issues and problems facing far too many vulnerable children in urban centers throughout the AsiaPacific region. In this paper, homeless children is used as shorthand for children who might transit to the street, children on the street, or children who previously lived on the street, with a variety of occupations, including beggar, rubbish picker, shoeshine boy or flower seller, sweat shop worker, sex worker, petty criminal, etc...

Street children must be provided tender care and psychological and emotional support, vocational support and good nutritive diet so that they are not exposed to occupational and health hazards. This seems not to be the case by the finding of the study and need to be improved.

A residential care Institution may not have resources in Indian context to provide all required professional services to the full according to the finding of the studies but achieving these targets requires careful understanding empathy and multi-disciplinary coordination and networking between various agencies that deals with child as the center of the Institution.

Focus group discussions are the best method for creating a conducive environment with a facilitation of an expert, such as a counselor, psychiatrist or a social worker for eliminating child abuse or other emotional problems in children; if needed an individual attention should also be focused to improve the mental health of these children.

Importantly, every child has the right to lead a life, free from discrimination, inequality and exploitation. This is the key to our residential care and foremost to nation building.

\section{REFERENCES}

[1] Christensen, S.K. (ed). 2002. A Tool Kit on Child Rights Programming. Copenhagen: Save the Children, Denmark.

[2] Connolly, M., and J. Ennew. 1996. Children out of place: special issue on working and street children. Childhood 3(2). May.

[3] Consortium for Street Children. 2001a. Advocacy Workshop Report. London: Consortium for Street Children.

[4] D'Souza b., Castelino 1., Madangopal D., (2002). A Demographic Profile of Street Children in Mumbai, Shelter Don Bosco Research And Documentation Center, Mumbai.

[5] Glenn Miles \& Paul Stephenson, Children in Residential Care and Alternatives, (Tearfund: 2001) 9.

[6] Kacker, L, et al (2007), Study on Child Abuse: India 2007, p 38-39. Ministry of Women and Child Development, Government of India, [Online] Available at: http://wcd.nic.in/childabuse.pdf. [Accessed 19 July 2009].

[7] Shrivastava M, (1995). Drug abuse amongst street children. Perspective in Social Work, 10(1): 11-17.

[8] Stonge, James H. ed. (1992). Educating Homeless Children and Adolescents: Evaluating Policy and Practice. Newbury Park, CA: Sage. .

[9] UNESCO/ICCB. 1995. Working with Street Children: Selected Case Studies from Africa, Asia and Latin America. Paris: UNESCO and ICCB (International Catholic Children's Bureau).

[10] UNICEF. 2002. UNICEF calls Global Response to Children Orphaned by AIDS Grossly Inadequate. Press Release, 2 December 2002. 